\title{
Factors associated with extubation time in coronary artery bypass grafting patients
}

Abbas Rezaianzadeh, Behzad Maghsoudi, Hamidreza Tabatabaee, Sareh Keshavarzi, Zahra Bagheri, Javad Sajedianfard, Hamid Gerami, Javad Rasouli

Background and Objectives: Cardiovascular diseases are the leading cause of death worldwide, with coronary artery disease being the most common. With increasing numbers of patients, Coronary Artery Bypass Grafting (CABG) has become the most common operation in the world. Respiratory disorder is one of the most prevalent complications of CABG. Thus, weaning off the mechanical ventilation and extubation are of great clinical importance for these patients. Some post-operative problems also relate to the tracheal tube and mechanical ventilation. Therefore, an increase in this leads to an increase in the number of complications, length of hospital stay, and treatment costs. Since a large number of factors affect the post-operative period, the present study aims to identify the predictors of extubation time in CABG patients using casualty network analysis. Method: This longitudinal study was conducted on 800 over 18 year old patients who had undergone CABG surgery in three treatment centers affiliated to Shiraz University of Medical Sciences. The patients' information, including pre-operative, peri-operative, and post-operative variables, was retrospectively extracted from their medical records. Then, the data was comprehensively analyzed through path analysis using MPLUS-7.1 software. Results: The mean of extubation time was $10.27+4.39$ hours. Moreover, extubation time was significantly affected by packed cells during the Cardiopulmonary Bypass (CPB), packed cells after CPB, inotrope use on arrival at ICU, mean arterial pressure 1st ICU, packed cells 1st ICU, platelets 1st ICU, Blood Urea Nitrogen 1st ICU, and hematocrit 1st ICU. Conclusion: Considering all of the factors under investigation, some peri-operative and post-operative factors had significant effects. Therefore, considering the postoperative factors is important for designing a treatment plan and evaluating patients' prognosis . 
1 Factors associated with extubation time in coronary artery bypass grafting patients

3 Abbas Rezaianzadeh ${ }^{1}$; Behzad Maghsoudi²; Hamidreza Tabatabaee ${ }^{1}$; Sareh Keshavarzi ${ }^{1}$; Zahra

4 Bagheri ${ }^{3}$; Javad Sajedianfard ${ }^{4}$; Hamid Gerami²; Javad Rasouli ${ }^{1 *}$

5 1. Department of Epidemiology, School of Health, Shiraz University of Medical Sciences, Shiraz, 6 Iran

72 .Department of anesthesia, Shiraz medical school, Shiraz University of Medical Sciences, Shiraz, 8 Iran

9 3. Department of Biostatistics, Shiraz medical school, Shiraz University of Medical Sciences, 10 Shiraz, Iran

114 .Department of Physiology, School of Veterinary Medicine, Shiraz University, Shiraz, Iran

12 *Corresponding Author: Javad Rasouli, Department of Epidemiology, School of Health, Shiraz 13 University of Medical Sciences, Shiraz, Iran. P.O.Box: 71645-111, Shiraz, I. R. Tel: +98149144478494

15 E-mail: rsljvd@yahoo.com 


\section{Abstract}

32 Background and Objectives. Cardiovascular diseases are the leading cause of death

33 worldwide, with coronary artery disease being the most common. With increasing numbers of 34 patients, Coronary Artery Bypass Grafting (CABG) has become the most common operation in 35 the world. Respiratory disorder is one of the most prevalent complications of CABG. Thus, 36 weaning off the mechanical ventilation and extubation are of great clinical importance for these 37 patients. Some post-operative problems also relate to the tracheal tube and mechanical ventilation. 38 Therefore, an increase in this leads to an increase in the number of complications, length of hospital 39 stay, and treatment costs. Since a large number of factors affect the post-operative period, the 40 present study aims to identify the predictors of extubation time in CABG patients using casualty 41 network analysis.

42 Method. This longitudinal study was conducted on 800 over 18 year old patients who had undergone CABG surgery in three treatment centers affiliated to Shiraz University of Medical

44 Sciences. The patients' information, including pre-operative, peri-operative, and post-operative variables, was retrospectively extracted from their medical records. Then, the data was comprehensively analyzed through path analysis using MPLUS-7.1 software.

47 Results. The mean of extubation time was $10.27 \pm 4.39$ hours. Moreover, extubation time was significantly affected by packed cells during the Cardiopulmonary Bypass (CPB), packed cells

49 after $\mathrm{CPB}$, inotrope use on arrival at ICU, mean arterial pressure 1st ICU, packed cells 1st ICU, 50 platelets 1st ICU, Blood Urea Nitrogen 1st ICU, and hematocrit 1st ICU.

\section{Conclusion.}


52 According our findings, some peri-operative and post-operative factors had significant effects.

53 Therefore, these factors must be considered for designing a treatment plan, patient care and 54 evaluating patients' prognosis.

55

\section{Introduction}

Cardiovascular diseases are the leading cause of death all around the world. Among these diseases, Coronary Artery Disease (CAD) has been introduced as the first and most common cause of mortality in all age groups (Archbold \& Curzen 2003; Go et al. 2014; Yu et al. 2015). According to the 2010 report by the American Heart Association (AHA), CAD accounted for 1 in every 6 deaths in the U.S. In addition, 379,555 Americans died as a result of CAD in 2010(Go et al. 2014). Nowadays, CAD is one of the most prevalent diseases resulting in hospitalization in the U.S. In U.S, more than 13 million individuals suffer from CAD(Chu et al. 2008). With an increase in the number of incidents of CAD, Coronary Artery Bypass Grafting (CABG) has become one of the most common operations worldwide, such that almost 500,000 CABG operations are performed in the U.S. every year(Branca et al. 2001; Dorsa et al. 2011).

Respiratory disorder is one of the most prevalent complications of CABG (Cohen et al. 2000; Faritous et al. 2011; Shahbazi \& Kazerooni 2012; Totonchi et al. 2014; Yende \& Wunderink 2002). The incident rate of respiratory disorders after CABG has been estimated to be $5-20 \%$, which leads to an annual cost of 2 million dollars(Christian et al. 2011). Prolonged Mechanical Ventilation (PMV) after CABG can increase morbidity and mortality rates as well as treatment costs; it may also decrease the quality of life(Cohen et al. 2000; Faritous et al. 2011; Shahbazi \& Kazerooni 2012; Totonchi et al. 2014). Advances in science and technology in the field of cardiac surgery have resulted in new techniques for treatment of these disorders. These techniques include new 
anesthesia methods, open heart surgery without using Cardiopulmonary Bypass (CPB), and less invasive CABG which have somewhat reduced the duration of surgery, extubation time, length of ICU stay, complications, and costs(Doering et al. 2000).

The present study aims at identifying pre-operative, peri-operative, and post-operative risk factors that relate to extubation time and it aims to determine their effectiveness in the prognosis of patients for increasing the care quality and improving CABG outcomes.

\section{Methods}

This observational, multicenter study was conducted after gaining approval of the Ethics Committee and Research Vice-Chancellor of Shiraz University of Medical Sciences (proposal No. 93-7247) for the collection of information from patients' medical records. The patients over 18 years old who had undergone open heart surgery in Shahid Faghihi, Al-Zahra, and Kowsar hospitals affiliated to Shiraz University of Medical Sciences (Shiraz southern of Iran) from April to September 2014 were enrolled into the study. The patients' pre-operative, peri-operative, and post-operative information was retrospectively extracted from their medical records and entered into the study checklist by two trained anesthesia staff of the cardiac operating room (Table 1). In order to ensure the accuracy of the information, the data extracted from $10 \%$ of the records was reviewed and matched with the related checklists. The records were re-checked in case of ambiguity. 800 cases overall were entered into the study.

In this study, the dependent variable was the length of intubation, which was considered to be the period between the patients' arrival at the ICU and their extubation (in hours). 
94 In the recent decades, many attempts have been made towards comprehensive investigation of

95 these variables. One of the most promising methods in this respect is structural equations and 96 multivariate analyses (Hox 2010; Hoyle 2014; Lleras 2005; Pearl 2000) .

97 Investigation of the complex relationships among variables requires utilization of methods, which

98 not only analyze $\mathrm{K}$ independent variables and $\mathrm{N}$ dependent variables simultaneously, but can also

99 show their mutual effects in a theory-based structure. One such method is a complex mathematical

100 and statistical combination of multivariate regression analysis; i.e., path analysis, which analyzes

101 the variables collected in a complex system (Hox 2010; Hoyle 2014; Karadag 2012; Lleras 2005;

102 Meehl \& Waller 2002; Streiner 2005). In the present study, path analysis was done using MPLUS-

1037.1 software to achieve the objectives and evaluate the intended theoretical model.

104 During a literature review, it was found that path analysis was performed over 5 stages, namely 105 model formulation, model identification, model estimation, model evaluation, and model 106 modification. Moreover, Root Mean Square Error of Approximation (RMSEA), Tucker-Lewis 107 Index (TLI), Comparative Fit Index (CFI), and Square Residual Standardized Root Mean (SRMR) 108 were used to assess the appropriateness of the designed model (Wang \& Wang 2012). Pearson and 109 Spearman correlation coefficients were used for univariate analyses and the means were compared 110 by an independent sample t-test. $\mathrm{P}<0.05$ was considered as statistically significant in all tests.

111 In order to carry out path analysis, first a theoretical model should be designed based on the 112 previous findings and researchers' assumptions to provide the basis for analyses. The theoretical 113 model based on pre-operative, peri-operative, and post-operative stages has been provided with 114 deep literature review, where the effects of different variables on the dependent variable 115 (extubation time) can be determined. 


\section{3. Results}

117 This longitudinal study was conducted on 800 patients who had undergone CABG surgery. The

118 results showed that the patients' ages ranged from 20 to 89 years old with a mean age of

$11959.26 \pm 11.60$ years. Most of the patients $483(60.4 \%)$ were male. The mean of extubation time was

$12010.27 \pm 4.39$ hours. The patients’ basic characteristics have been presented in Table 2 . In addition,

121 the results of the univariate analysis of qualitative and quantitative risk factors of the study have

122 been shown in Tables 3 and 2 .

123 As Table 2 depicts, some factors correlated significantly with extubation time. The results of 124 univariate analysis also indicated the great importance of pre-operative and post-operative risk 125 factors.

126 The results of the independent sample t-test (Table 3) revealed that the mean of extubation time 127 was higher in females and in patients with diabetes, hypertension, and Chronic Obstructive 128 Pulmonary Disease (COPD), but the difference was not statistically significant $(\mathrm{P}>0.05)$. 129 Conversely, the mean of extubation time was significantly higher in the patients who had received 130 inotrope compared to those who had not $(\mathrm{P}<0.001)$. In addition, the mean age of the patients who

131 had received inotrope was significantly higher in comparison to those who had not $(\mathrm{P}<0.037)$.

132 Considering multiple relations and the probability of the impact of confounding factors, the 133 interpretation of univariate analysis results should be done with due caution. In order to control 134 the effects of the confounding factors and assess the multiple associations, path analysis was used 135 and the results were presented in Table 4. In path analysis, direct, indirect, and total effects can be 136 evaluated and confounding effects can be controlled. Therefore, the results can be applied with 137 greater certainty. The variables with one significant effect (direct, indirect, or total) have been 
138 shown in Table 4. It should be noted that total effects are more important on the basis of decision-

139 making. Furthermore, values related to effect size of the study's variables are in fact the

140 standardized coefficient, which is used for similarity and comparability of the measurement units

141 of all the variables. Interpretation of this coefficient is the same as that of the regression coefficient

142 and its value varies between -1 and +1 .

143 According to the results of path analysis, presented in Table 4, packed cells during CPB and packed

144 cells after CPB (among peri-operative variables) and inotrope use on 1h ICU (arrival to ICU),

145 mean arterial pressure on $1 \mathrm{~h} \mathrm{ICU}$, pack cell 1h ICU, platelet 1h ICU, Blood Urea Nitrogen (BUN)

146 1h ICU, and hematocrit 1st ICU (among post-operative variables) were effective on extubation

147 time $(\mathrm{P}<0.05)$. Yet, some of the risk factors had significant direct or indirect effects on extubation

148 time, which were modified in computation of the total effects.

149 The final model of the relationships among the factors affecting the dependent variable (extubation

150 time) and their effect paths have been presented in Figure 1. It should be mentioned that the path

151 coefficients representing the direct effects, and standard deviation of each variable in each

152 corresponding path, have been shown in this model. Mediator variables have also been determined.

153 Based on the software output, RMSEA $=0.036$, CI $0.90(0.021-0.046), \mathrm{CFI}=0.910, \mathrm{TLI}=0.901$, and

$154 \mathrm{SRMR}=0.016$. Considering the proposed values for decision-making (TLI/CFI 1 and

155 SRMR/RMSEA<0.05) (Wang \& Wang 2012), the designed model had acceptable appropriateness.

156 According to the number of variables of the study, to ensure enough power of the study, using the

157 R software for power analysis, the results showed that the power of the study was 0.81 , indicating

158 its adequacy are the recommended amounts.

\section{Discussion}


160 In the present study, none of the pre-operative factors had significant impacts on extubation time.

161 Among these variables, sex and previous history of diabetes mellitus, hypertension, and

162 hemoglobin pre-operation had significant direct or indirect effects on the variable under study.

163 However, considering various effects with different paths and directions, their total effects were

164 not statistically significant (Table 4). In the study by Suematsu et al.(Suematsu et al. 2000), the

165 results of univariate analysis indicated that none of the preoperative factors (age, sex, Body Mass

166 Index (BMI), smoking, hypertension, hyperlipidemia, diabetes, COPD, renal disease, liver disease,

167 and EF) had significant effects. Age was only found to be significantly effective in multivariate

168 analysis. Similarly, Cheristian et al. (Christian et al. 2011) reported that COPD, diabetes,

169 hypertension, sex, and BMI had significant effects in univariate analysis of the pre-operative

170 variables, but only sex was significantly effective in multivariate analysis.

171 The findings of univariate analysis in the current study showed that, among the peri-operative

172 factors, anesthesia duration, pre-anesthesia mean arterial pressure, total pump time, inotrope use

173 before $\mathrm{CPB}$, inotrope use during $\mathrm{CPB}$, inotrope use after $\mathrm{CPB}$, packed cells after $\mathrm{CPB}$, packed

174 cells during CPB, and lowest temperature on CPB had significant effects. However, only packed

175 cells during CPB and packed cells after CPB had significant effects in the final model (Table 4).

176 In the research by Cheristian et al.(Christian et al. 2011), the results of univariate analysis of peri-

177 operative factors demonstrated that anesthesia time, operation time, lowest temperature, and

178 transfusion were significantly effective. In multivariate analysis, however, only anesthesia time

179 had a significant effect.

180 Considering the post-operative factors, the results of univariate analysis demonstrated the 181 significant effects of inotrope use on arrival to ICU, inotrope use on $1 \mathrm{~h} \mathrm{ICU,} \mathrm{mean} \mathrm{arterial} \mathrm{pressure}$ 182 on ICU admission, urinary output $1 \mathrm{~h}$ ICU, packed cells $1 \mathrm{~h}$ ICU, platelets $1 \mathrm{~h}$ ICU, creatinine $1 \mathrm{st}$ 
183 ICU, BUN 1st ICU, and hematocrit 1st ICU. Only inotrope use on 1h ICU, mean arterial pressure

184 on $1 \mathrm{~h}$ ICU, packed cells $1 \mathrm{~h}$ ICU, platelets $1 \mathrm{~h}$ ICU, BUN 1st ICU, and hematocrit 1st ICU had 185 significant effects in path analysis (Table 4).

186 Other studies have also revealed the impacts of transfusion and inotrope use on extubation time 187 (Christian et al. 2011; Faritous et al. 2011; Scott et al. 2008; Shahbazi \& Kazerooni 2012; Suematsu et al. 2000; Totonchi et al. 2014). Up to now, there has been much debate on the risks of packed red blood cell transfusion. For instance, a review study by David and Gerber (Gerber 2012) demonstrated the high prevalence of packed red blood cell transfusion, post-operative mechanical ventilation, and its related respiratory disorders in CABG patients, which is in line with the results of the present study. Similarly, Vamvakas and Carven (Vamvakas \& Carven 2002) conducted a study on $416 \mathrm{CABG}$ patients to assess the effects of packed red blood cell transfusion and platelet, plasma, and total fluid volumes on post-operative mechanical ventilation. The study's results revealed that only packed red blood cell transfusion was significantly associated with postoperative mechanical ventilation.

Evidence has indicated that some factors, such as age, sex, respiratory status, and BMI, impact on extubation time in patients undergoing open heart surgery(Chu et al. 2008; Shahbazi \& Kazerooni 2012). Yet, contradictory results have been obtained in this regard from different studies. For instance, some studies have shown the role of age and sex, but some others have not (Azarfarin et al. 2014; Forouzannia et al. 2011; Ghotkar et al. 2006; Hein et al. 2006). The difference in the results could be attributed to differences in methodologies, statistical methods, and sample sizes in various studies. Moreover, the physiological factors under investigation have multiple relations and may cause both positive and negative effects. Therefore, not accurately controlling the confounding variables could deflect the results. The researchers of the present study considered a 
206 large number of pre-operative, peri-operative, and post-operative factors, which were thought to 207 have probable effect, and considered all the associations as a casualty network, and took all the 208 mutual effects into account to provide a proper interpretation of the relationships. In complex 209 relations, each variable can play the role of dependent and independent variables at the same time, 210 and path analysis has the capability of such presuppositions (Lleras 2005; Meehl \& Waller 2002;

211 Wang \& Wang 2012). Thus, in addition to having effect through different paths, a factor can have 212 both positive and negative effects in a network. In this case, the outcome of these effects 213 determines the factor's final impact on the final outcome.

214 The findings of our study showed that utilization of blood products and inotrope could increase 215 extubation time, while the measures increasing the patients' mean arterial pressure and hematocrit 216 in ICU, could decrease this time in the CABG patients.

217 Some researchers have referred to the impact of differences between the surgeon and 218 anesthesiologist on the operation outcome. However, this was not taken into account in this study 219 due to some limitations. Hence, further studies with larger sample sizes are recommended to be conducted in other centers using similar and even more advanced analytical methods in order to gain a deeper understanding of extubation time prognostic factors. In addition, future studies are suggested to be performed on the complications of delayed extubation, its effective factors, and contribution of each factor to different stages of the process to prevent unpleasant outcomes.

\section{Acknowledgement}

This article was extracted from a $\mathrm{PhD}$ dissertation in Epidemiology approved by Shiraz University of Medical Sciences. Hereby, the authors would like to thank the Research Vice-Chancellor of the 
227 University and personnel and authorities of the study hospitals for their cooperation in data

228 collection.

229

230

231

232

233

234

235

236

237

238

239

240

241

242

243

244

245

246

247

248

249

250

251

252

253

254

255

256

257

258

259

260

261

262

\section{References:}

Archbold R, and Curzen N. 2003. Off-pump coronary artery bypass graft surgery: the incidence of postoperative atrial fibrillation. Heart 89:1134-1137.

Azarfarin R, Ashouri N, Totonchi Z, Bakhshandeh H, and Yaghoubi A. 2014. Factors Influencing Prolonged ICU Stay After Open Heart Surgery. Research in cardiovascular medicine 3.

Branca P, McGaw P, and Light RW. 2001. Factors associated with prolonged mechanical ventilation following coronary artery bypass surgery. CHEST Journal 119:537-546.

Christian K, Engel AM, and Smith JM. 2011. Predictors and outcomes of prolonged ventilation after coronary artery bypass graft surgery. The American Surgeon 77:942-947.

Chu D, Bakaeen FG, Wang XL, LeMaire SA, Coselli JS, and Huh J. 2008. Does the duration of surgery affect outcomes in patients undergoing coronary artery bypass grafting? The American Journal of Surgery 196:652-656.

Cohen AJ, Katz MG, Frenkel G, Medalion B, Geva D, and Schachner A. 2000. Morbid results of prolonged intubation after coronary artery bypass surgery. CHEST Journal 118:1724-1731.

Doering LV, Esmailian F, and Laks H. 2000. Perioperative predictors of ICU and hospital costs in coronary artery bypass graft surgery. CHEST Journal 118:736-743.

Dorsa AG, Rossi AI, Thierer J, Lupiañez B, Vrancic JM, Vaccarino GN, Piccinini F, Raich H, Bonazzi SV, and Benzadon M. 2011. Immediate extubation after off-pump coronary artery bypass graft surgery in 1,196 consecutive patients: feasibility, safety and predictors of when not to attempt it. Journal of cardiothoracic and vascular anesthesia 25:431-436.

Faritous ZS, Aghdaie N, Yazdanian F, Azarfarin R, and Dabbagh A. 2011. Perioperative risk factors for prolonged mechanical ventilation and tracheostomy in women undergoing coronary artery bypass graft with cardiopulmonary bypass. Saudi journal of anaesthesia 5:167.

Forouzannia SK, Abdollahi MH, Mirhosseini SJ, Hadadzadeh M, Hosseini H, Moshtaghion SH, Naserzadeh N, and Ghoraishian SM. 2011. Perioperative predictors and clinical outcome in early and late ICU discharge after off-pump coronary artery bypass surgery. Acta Medica Iranica 49:307-309.

Gerber DR. 2012. Risks of packed red blood cell transfusion in patients undergoing cardiac surgery. Journal of critical care 27:737. e731-737. e739. 
263 Ghotkar SV, Grayson AD, Fabri BM, Dihmis WC, and Pullan DM. 2006. Preoperative calculation 264 of risk for prolonged intensive care unit stay following coronary artery bypass grafting. $J$ 265 Cardiothorac Surg 1:14.

266 Go AS, Mozaffarian D, Roger VL, Benjamin EJ, Berry JD, Blaha MJ, Dai S, Ford ES, Fox CS, 267 and Franco S. 2014. Executive summary: heart disease and stroke statistics--2014 update: a report 268 from the American Heart Association. Circulation 129:399.

269 Hein OV, Birnbaum J, Wernecke K, England M, Konertz W, and Spies C. 2006. Prolonged 270 intensive care unit stay in cardiac surgery: risk factors and long-term-survival. The Annals of 271 thoracic surgery 81:880-885.

272 Hox J. 2010. Multilevel analysis: Techniques and applications: Routledge.

273 Hoyle RH. 2014. Handbook of Structural Equation Modeling: Guilford Publications.

274 Karadag E. 2012. Basic features of structural equation modeling and path analysis with its place 275 and importance in educational research methodology. Bulgarian Journal of Science and Education 276 Policy 6:194.

277 Lleras C. 2005. Path analysis. Encyclopedia of social measurement 3:25-30.

278 Meehl PE, and Waller NG. 2002. The Path Analysis Controversy: A new statistical approach to 279 strong appraisal of verisimilitude. Psychological methods 7:283.

280 Pearl J. 2000. Models, reasoning and inference. Cambridge University Press Cambridge, UK:.

281 Scott BH, Seifert FC, and Grimson R. 2008. Blood transfusion is associated with increased

282 resource utilisation, morbidity and mortality in cardiac surgery. Annals of cardiac anaesthesia 283 11:15.

284 Shahbazi S, and Kazerooni M. 2012. Predictive factors for delayed extubation in the intensive care 285 unit after coronary artery bypass grafting; a Southern Iranian experience. Iranian journal of 286 medical sciences 37:238.

287 Streiner DL. 2005. Finding our way: an introduction to path analysis. The Canadian Journal of 288 Psychiatry/La Revue canadienne de psychiatrie.

289 Suematsu Y, Sato H, Ohtsuka T, Kotsuka Y, Araki S, and Takamoto S. 2000. Predictive risk 290 factors for delayed extubation in patients undergoing coronary artery bypass grafting. Heart and 291 vessels 15:214-220.

292 Totonchi Z, Baazm F, Chitsazan M, Seifi S, and Chitsazan M. 2014. Predictors of Prolonged 293 Mechanical Ventilation after Open Heart Surgery. Journal of cardiovascular and thoracic 294 research 6:211.

295 Vamvakas E, and Carven J. 2002. Allogeneic blood transfusion and postoperative duration of 296 mechanical ventilation: effects of red cell supernatant, platelet supernatant, plasma components 297 and total transfused fluid. Vox sanguinis 82:141-149.

298 Wang J, and Wang X. 2012. Structural Equation Modeling: Applications Using Mplus: Wiley.

299 Yende S, and Wunderink R. 2002. Validity of scoring systems to predict risk of prolonged 300 mechanical ventilation after coronary artery bypass graft surgery. CHEST Journal 122:239-244.

301 Yu Q, Li H, Li L, Wang S, and Wu Y. 2015. Correlation between genetic polymorphism of matrix 302 metalloproteinase-9 in patients with coronary artery disease and cardiac remodeling. 


\section{Table 1 (on next page)}

Relevant pre-, perio- and post-operative data collected for all cases 
1 Table1.Relevant pre-, perio- and post-operative data collected for all cases

\begin{tabular}{|c|c|c|}
\hline Preoperative data & Perioperative data & post-operative data \\
\hline 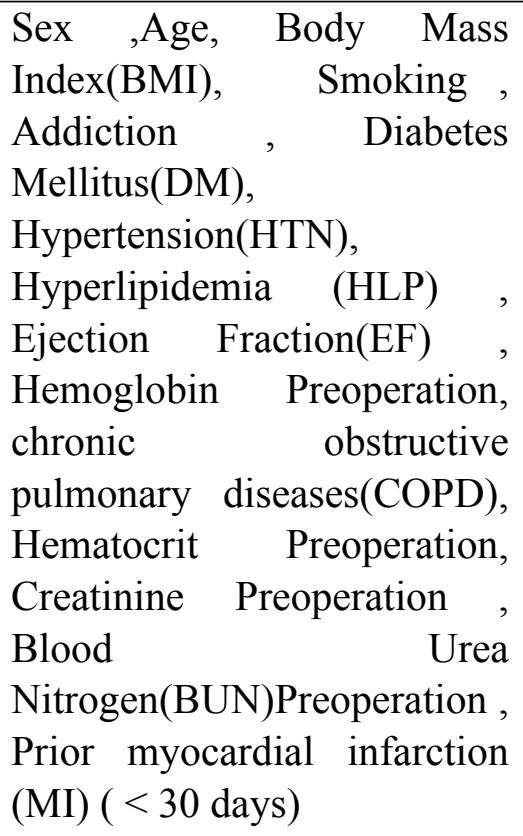 & $\begin{array}{l}\text { Anesthesia Duration, Operation } \\
\text { Duration , Mean Arterial } \\
\text { Pressure ( MAP) pre Anesthesia, } \\
\text { MAP before cardiopulmonary } \\
\text { bypass( CPB), Inotrope use } \\
\text { Before CPB, Total Pump Time, } \\
\text { Cross Clamp Time, Urinary Out } \\
\text { put before CPB, Hemofilter } \\
\text { Volume, Inotrope use During } \\
\text { CPB, Inotrope use After CPB, } \\
\text { MAP at end of Operation, Pack } \\
\text { Cell after CPB, Platelet after } \\
\text { CPB, activated clotting time/ } \\
\text { second, Urinary output during } \\
\text { CPB, Pack Cell during CPB, } \\
\text { Lowest Temperature on CPB }\end{array}$ & $\begin{array}{l}\text { Inotrope use arrival to ICU, } \\
\text { MAP admission ICU, } \\
\text { Urinary output first 1h ICU, } \\
\text { Pack Cell 1h ICU, Platelet } 1 \mathrm{~h} \\
\text { ICU, Creatinine 1st ICU } \\
\text { (arrival to ICU), Blood Urea } \\
\text { Nitrogen (BUN) 1st ICU } \\
\text { (arrival to ICU), hematocrit } \\
\text { 1st ICU (arrival to ICU), }\end{array}$ \\
\hline
\end{tabular}

2 


\section{Table 2 (on next page)}

Baseline quantitative characteristics of the patients and univariate analysis result with extubation time 
1 Table2. Baseline quantitative characteristics of the patients and univariate analysis result with extubation

2

\begin{tabular}{|c|c|c|c|}
\hline \multicolumn{4}{|c|}{ time } \\
\hline Risk factors & Mean \pm SD & Pearson Correlation Coefficient & P-Value \\
\hline Age* & $59.26 \pm 11.60$ & 0.25 & $<0.001$ \\
\hline Body Mass Index* & $25.75 \pm 4.18$ & -0.17 & $<0.001$ \\
\hline Ejection Fraction* & $49.19 \pm 10.51$ & -0.09 & 0.01 \\
\hline Hemoglobin Preoperation & $11.81 \pm 1.78$ & -0.07 & 0.07 \\
\hline Hematocrit Preoperation* & $35.04 \pm 5.37$ & -0.08 & 0.03 \\
\hline Creatinine Preoperation* & $1.08 \pm 0.35$ & 0.12 & 0.00 \\
\hline BUN Preoperation* & $17.54 \pm 6.29$ & 0.20 & $<0.001$ \\
\hline Anesthesia Duration* & $4.49 \pm 0.73$ & 0.08 & 0.02 \\
\hline Operation Duration & $3.08 \pm 0.70$ & 0.06 & 0.12 \\
\hline Mean Arterial Pressure pre Anesthesia* & $99.93 \pm 14.28$ & -0.09 & 0.01 \\
\hline MAP before CPB & $71.25 \pm 12.21$ & -0.01 & 0.82 \\
\hline Total Pump Time* & $70.38 \pm 20.71$ & 0.10 & 0.01 \\
\hline Cross Clamp Time & $40.12 \pm 13.55$ & 0.03 & 0.39 \\
\hline Urinary Output before $\mathrm{CPB}$ & $240.54 \pm 251.94$ & -0.01 & 0.88 \\
\hline Hemofilter Volume & $1588.74 \pm 776.33$ & 0.02 & 0.57 \\
\hline MAP at end of Operation & $75.93 \pm 9.60$ & -0.06 & 0.07 \\
\hline Pack Cell after CPB* & $0.48 \pm 0.60$ & 0.11 & 0.00 \\
\hline Platelet after CPB & $0.06 \pm 0.51$ & 0.05 & 0.19 \\
\hline Urinary Output during CPB & $532.18 \pm 394.18$ & -0.06 & 0.12 \\
\hline Pack Cell during $\mathrm{CPB}^{*}$ & $0.88 \pm 0.85$ & 0.14 & $<0.001$ \\
\hline Lowest Temperature on $\mathrm{CPB}^{*}$ & $33.04 \pm 1.16$ & -0.08 & 0.03 \\
\hline MAP admission ICU* & $79.48 \pm 14.77$ & -0.18 & $<0.001$ \\
\hline MAP on $6 \mathrm{~h} \mathrm{ICU*}$ & $79.10 \pm 10.67$ & -0.15 & $<0.001$ \\
\hline Urinary Output first $6 \mathrm{~h}$ ICU* & $1403.67 \pm 614.89$ & -0.16 & $<0.001$ \\
\hline Platelet 1h ICU* & $0.25 \pm 0.99$ & 0.12 & 0.00 \\
\hline Creatinine 1st ICU (arrival to ICU)* & $1.00 \pm 0.31$ & 0.17 & $<0.001$ \\
\hline BUN 1st ICU (arrival to ICU)* & $16.15 \pm 5.91$ & 0.23 & $<0.001$ \\
\hline Het 1st ICU (arrival to ICU)* & $31.85 \pm 4.37$ & -0.15 & $<0.001$ \\
\hline Extubation hours after arrival in ICU & $10.27 \pm 4.39$ & - & - \\
\hline
\end{tabular}


3 *Statistically significant ( $\mathrm{p}$-value $<0.05)$,

4 


\section{Table 3(on next page)}

Baseline qualitative characteristics of the patients and univariate analysis result with extubation time 
1 Table3. Baseline qualitative characteristics of the patients and univariate analysis result with extubation

2

3

Risk factors time

$$
4
$$

$4 \frac{\text { Sex }(\text { Male/Female })}{\text { Smoking(yes/no) }}$

5

6 Hypertension(yes/no)

Addiction(yes/no)

10.4
7
chronic obstructive pulmonary diseases(yes/no)

8 Any arrhythmia(yes/no)

$10.22 \pm 4.69 / 10.31 \pm 4.08 \quad 0.762$
9
10 Inotrope use During $\mathrm{CPB}(\mathrm{yes} / \mathrm{no})^{*}$
Inotrope use After $\mathrm{CPB}(\mathrm{yes} / \mathrm{no}) *$

11 Inotrope use arrival to ICU(yes/no)*

12 Inotrope use on $6 \mathrm{~h} \mathrm{ICU}($ yes/no)*

$13 *$ Statistically significant $(\mathrm{p}$-value $<0.05)$

14 


\section{Table 4(on next page)}

Standardized Direct, Indirect and total risk factors effects on Extubation time 
Table 4. Standardized Direct, Indirect and total risk factors effects on Extubation time

\begin{tabular}{|c|c|c|c|c|c|c|}
\hline Risk factor & $\begin{array}{l}\text { Direct } \\
\text { effect }\end{array}$ & P-Value & Indirect effect & P-Value & $\begin{array}{l}\text { Total } \\
\text { effect }\end{array}$ & P-Value \\
\hline Sex & 0.014 & 0.779 & 0.056 & $0.011^{*}$ & 0.070 & 0.123 \\
\hline Diabetes Mellitus & -0.094 & $0.017 *$ & 0.019 & $0.037^{*}$ & -0.076 & 0.058 \\
\hline Pack Cell during CPB & 0.191 & $<0.001 *$ & -0.017 & $0.105^{*}$ & 0.174 & $0.001 *$ \\
\hline Hemoglobin Preoperation & 0.126 & 0.388 & -0.099 & $0.020^{*}$ & 0.027 & 0.853 \\
\hline Pack Cell after CPB & 0.102 & $0.008^{*}$ & -0.006 & 0.254 & 0.096 & $0.013 *$ \\
\hline Hypertension & 0.035 & 0.403 & 0.021 & $0.027 *$ & 0.056 & 0.181 \\
\hline Bun1stICU & 0.128 & $0.019 *$ & 0.02 & 0.325 & 0.147 & $0.004 *$ \\
\hline HCT1stICU & -0.091 & $0.038^{*}$ & - & - & -0.091 & $0.038^{*}$ \\
\hline Inotrope use arrival to ICU & 0.129 & $0.039 *$ & - & - & 0.129 & $0.039 *$ \\
\hline MAP6hICU & -0.123 & $0.002 *$ & - & - & -0.123 & $0.002 *$ \\
\hline Platelet 6h ICU & 0.119 & $0.003 *$ & - & - & 0.119 & $0.003 *$ \\
\hline Pack Cell 6h ICU & 0.115 & $0.007 *$ & - & - & 0.115 & $0.007 *$ \\
\hline
\end{tabular}

$3 \quad *$ statistically significant $(\mathrm{p}$-value $<0.05)$

4 


\section{1}

Causal network diagram of Influenced factors of Extubation time

(RMSEA $=0.036, \mathrm{CFI}=0.910, \mathrm{TLI}=0.901, \mathrm{SRMR}=0.016) *$ The arrow indicator values are standardized direct effects with standard deviation

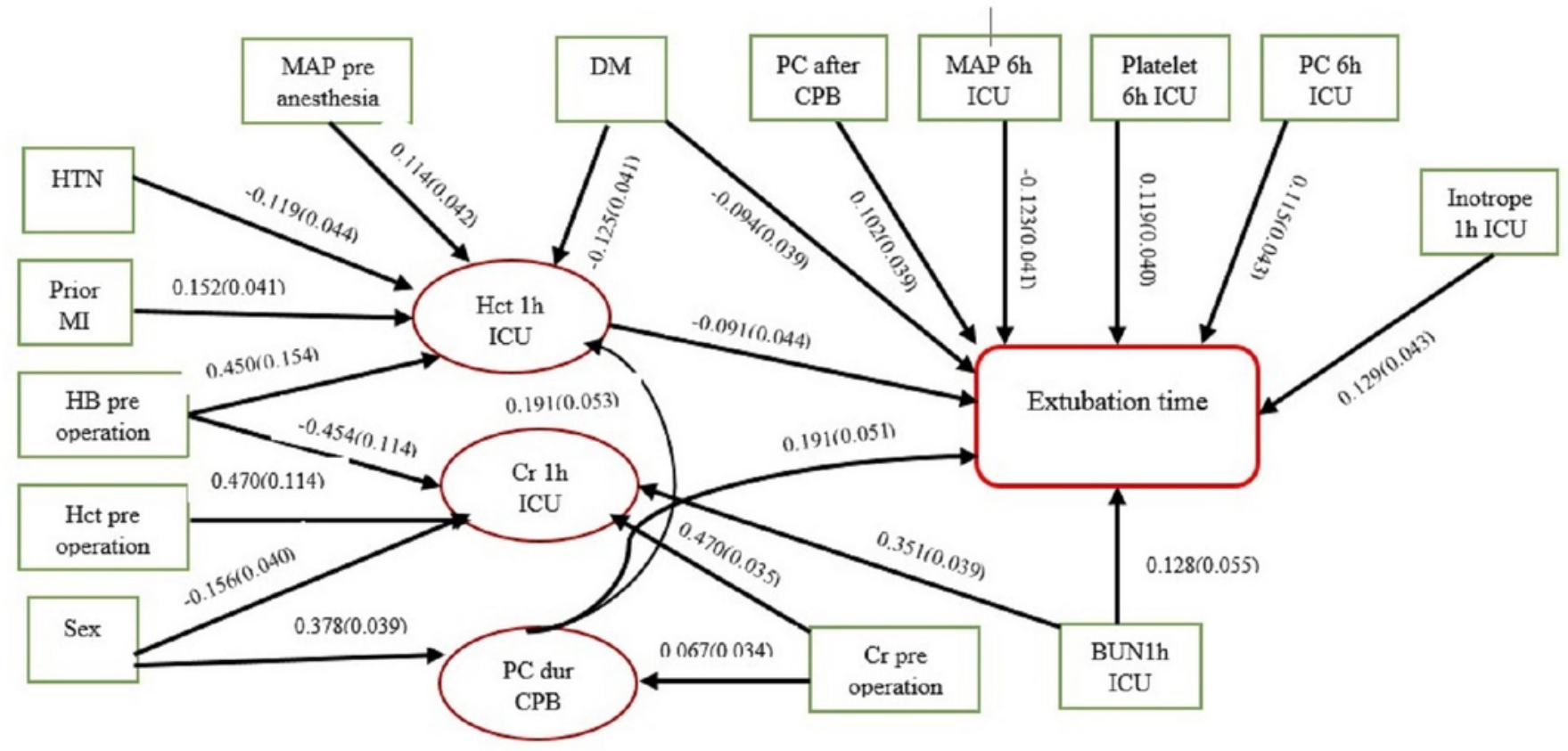

